\title{
The Role of Researcher Competencies in Delivering Successful Research
}

\author{
Ayman Ahmad Abu Rumman \\ Assistant Professor- Business School, Al-ahliyya Amman University, Jordan \\ Ahmad Fathi Alheet \\ Assistant Professor- Business School, Al-ahliyya Amman University, Jordan
}

\begin{abstract}
This research aims to identify the role of researcher competencies in delivering successful research and most important competencies that must an individualpossess to become a good researcher. However,some researchers have confused skills with competencies. For example, in some previous studies, data collection and analysis were reported as competencies, yet these are skills that can be acquired through training. $n$ contrast, competencies are innate talents present at birth within person. The main results of this study mention thatresearcher competencies differ from researcher skills. Based on these results, the authorssuggest recommendation such as Universities should pay more attention to the research process. And Arab countries should allocate a special budget to support scientific research.
\end{abstract}

Keywords: Competencies, Successful Research Projects, Researchers

DOI: $10.7176 / \mathrm{IKM} / 9-1-05$

\section{Introduction}

The term research as used in this study refers to applied research, both academic and business. The research beneficiaries vary between these two respective types. For academic research, the beneficiaries include universities, scientific institutions, and student undergraduates, while the main beneficiaries of business research include the business sectors, investors, and creditors. These benefits depend on many factors, such as the research purpose, its topic, the validity of its findings, and the possibility of applying these findings to the real world. The ability to effectively judge these factors depends heavily on the researcher's competencies in terms of the validity of the research for publication and the application of its results by beneficiaries. Therefore, this study is concerned with determining which researcher competencies contribute most to achieving this ambition.

Why is Research Important?

1. A Tool for Building Knowledge and for Facilitating Learning

2. Means to Understand Various Issues and Increase Public Awareness

3. An Aid to Business Success

4. Means to Find, Gauge, and Seize Opportunities

5. Reading, Writing, Analyzing, and Sharing Valuable Information

6. Nourishment and Exercise for the Mind 


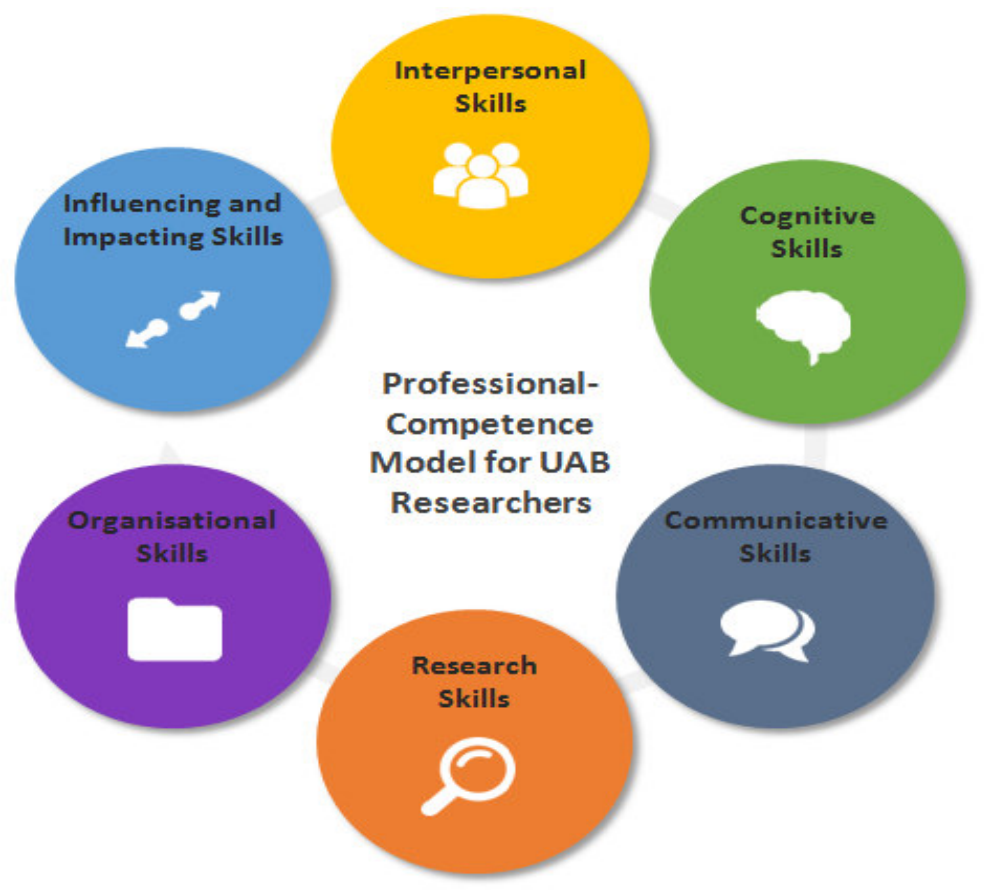

Adapted from ESF (2009) and OCDE (2012)

\subsection{Problem Statement and Questions}

This study investigates whether the benefit of scientific research depends on the researcher's ability to identify and understand the problem in question. This problem will be addressed through the following questions.

1- What are the basic skills that a researcher must possess?

2- What are the scientific research characteristics that make research results useful to others?

3- How cana researcher's skills be linked to the benefits from the search results?

\subsection{Study Importance}

As Abu Ameer (2012) noted, Israel, the U.S.A, and Japan are the most prolific spenders on scientific research in the world. Hence, this study is important because it focuses on the skills required to produce useful scientific research. The main purpose of this study is to identify the competencies required to produce useful research and rank them according to their significance.

\section{Methodology}

This qualitative study was conducted by reviewing a number of related studies from previous literature to identify the researcher competencies that received the author's largest focus.

\subsection{Theoretical Framework and Literature Review}

Scientific research may be conducted in several forms, such as surveys, case studies, and econometric studies. All these approaches require data collection through different methods and sources, taking into account that the utilized data collection method must be appropriate to the research problem and population (Lo Bondoc- Wood, et al., 2013). Scientific research is also carried out through several successive steps that should be listed under 
the research design (Hakim, 2000, p.3). Most of the literature agrees that the most important steps of the research process are as follows:

\section{Defining the problem}

In this step, the researcher should examine the literature to determine risk, promotive factors, and protective factors related to the problem (Fraser, 2004). Some researchers (Gutman et al., 2002) noted that these factors should be legal to avoid the risk of legal problems. This task requires the researcher to possess proper legal knowledge (Bell, 2010, p.10). Additionally, the researcher should have good computer skills to assist in reviewing the related literature.

\section{Data collection}

(Boote and Beile, 2005) state thatthe researcher should specify the data collection methods and potential sources. Usually, the researcher acquires secondary data from the literature, such as books, articles, previous research, and others. However, primary data should build collaboration between the practitioners and the researcher to provide alternative solutions for the problem This requires the researcher to specify the data collection instruments, which may include questionnaires or interview. Accordingly, an effective researcher needs qualitative and quantitative data acquisition skills, including the ability to formulate questions in such a way as to collect sufficient data (Thomas, 2004, p. 8). Other authors have separated the literature review process from this stage (Blankenship, 2010).

\section{Defining the terms}

At this stage, the researcher should help readers understand the words and phrases used in the research objectives. For example, if the purpose is to widen the market share of a company, the researcher must define the term "market share." This stage is highly important for both the readers and the beneficiaries of the research findings (Kothari, 2004).

\section{Accurate identification of the study population}

The study of a particular phenomenon requires a determination of who will be the subjects of this study (called the study community or population). This population may consist of individuals, products, companies, universities, or others. Therefore, the researcher must carefully define the study population to reach a meaningful outcome. For example, if the goal of a survey is to measure the degree of job satisfaction at a company, the population should be the employees themselves rather than the company. However, if the research purpose is to explore the impact of sales volume on profitability, the study population will be sales volume compared to profits across a time series. Some researchers have stated that a larger population is a better fit for generalized research on several groups of beneficiaries (Oleary, 2004, p. 57).

\section{Data analysis}

Thecollected data should be analysed to achieve the objectives. These objectives include answering the research questions, testing the hypotheses, and reporting final findings that provide alternative solutions to the research problem. For example, suppose that the research problem is to study the weaknesses in English language communication among Arab students in the university (initially believed to be due to a lack of sustainable 
practice). The quantitative data was collected using a questionnaire on Arab students who formed the study community.

Here, the researcher must have sufficient insight and conscious knowledge to deduce solutions to the problem from the collected views of the respondents.

Therefore, this action requires discipline to generate a review that ensures the researcher relied on the data analysis (Bell, 2010, p. 104). The analysis may lead the researcher to propose some solutions to the problem, including modifying the curriculum, changing the teaching method from indoctrination to participation, and the employment of more skilled teachers.

\section{Discussion}

This section aims to discuss the prevailing opinions in the literature concerning the competencies and abilities necessary for researchers. Some authors focused on researchers' comprehension skills, because such skills help researchers summarize the existing literature (Boote and Beile, 2005). Others note that while the literature is not exhaustive, it may indicate how previous researchers have addressed the research problem (Taylor, 2011). Viger (2016) listed 6 necessary researcher skills, including humility and openness to criticism, building a social network, working hard and smart, having clear goals, stepping out of the comfort zone, having good writing skills, and having the ability to form conclusions. The author believes that this is an example of where Viger has confused competencies and research requirements: the only competency in his list is good writing skills, while the others are necessary requirements for performing research. According to Grey (2013), the most important competency of a good researcher is his or her ability to understand the problem to be able to develop that same understanding in others.

The researcher believes that competencies are different from skills, because skills can be acquired through training but competencies are similar to talents (especially innate talents). Forunier and Lafon (2016) noted that the main or tacit competencies from the viewpoints of their survey respondents were a critical mind and perseverance, while the knowledge and skills required for the various research stages can be acquired through training and practise (Meyers et al., 2013).

\section{Results}

This study reaches the following results:

1- Researcher competencies are different from researcher skills, because skills can be acquired through training but competencies are innate.

2- The most important competencies are a critical mind and perseverance.

3- Good researchers require many skills, of which the most important are the ability to understand a problem, the ability to develop others' understanding of the problem, good writing skills and clear communication.

4- Good researchers have critical thinking with Non-bias

\section{Recommendations}

1- Universities should pay more attention to the research process. 
2- Arab countries should allocate a special budge to support scientific research.

3- Arab Universities should focus on teaching English to enable researchers to examine the literature.

\section{References}

1- Abu Amir, Adnan (2012). Scientific Research in Israel and Decision - Making, Al Jazzera Media Network.

2- Bell, Judith (2010). Doing Your Research Project, A guide for first-time researchers in education, health and social science. Fifth Edition. McGraw-Hill House.

3- Blankenship, Diane (2010). Applied research and evaluation methods in recreation, p. 17.

4- Fournior, Durette and Lafon, M. (2016). The Core Competencies of PHDs. Studies in Higher Education, 41.8. 1355-1370.

5- Fraser, M. W. (2004). Risk and Resilience in Childhood an Ecological Perspective, $2^{\text {nd }}$ ed. Washington, Dc: NASW press.

6- Gray, David (2013). Doing research in the real world. $2^{\text {nd }}$ edition, sage, p. 33.

7- Gutman, Leslie, et al (2002). The Academic Achievement of African American Students during Early Adolescence: An Examination of Multiple Risks, Promotive and Protective Factors. American Journal of Community Psychology, Vol. 30, No. 3, 367-399.

8- Hakim, Catherine (2000). Research Design, Successful designs for social and economic research, Second Edition, Rout ledge, Taylor and Francis Group.

9- Kothari, C. R. (2004). Research methodology: methods and techniques, $2^{\text {nd }}$ edition, p.1.

10- Lo Biondo-Wood, Geri et al (2013). Nursing Research in Canada, Methods, Critical Appraisal, and Utilization, Third Edition, Elsevier Canda, Ltd.

11- Meyers, M. et al (2013). Innate or Acquired? Theoretical Considerations and their Implications for talent management. Human Resources Management Review, 23(4), 305-321.

12- Oleary, zina (2004). The essential guide to doing research, Sage publication Inc.

13- Roberts, P. (2006). Reliability and validity in research. Nursing standard, 20(44), 41-45.

14- Taylor, Jodie (2011). The Intimate insider: Negotiating the ethics of friendship when doing insider research; Journal of Qualitative Research, 11(1). pp. 3-22.

15- Thomas, Alan (2004). Research skills for management studies. Rout ledge, London.

16- Vigor, philippe (2016). Six important skills to become a successful researcher. Available at: www.dataminingphlippe-fournior-viger.com 